\title{
Affect and Engagement in STEM Education
}

\author{
Catherine Attard, Centre for Educational Research, Western Sydney University \\ Peter Grootenboer, Griffith University \\ Elise Attard, Centre for Educational Research, Western Sydney University \\ Alexandra Laird, Griffith University
}

\section{Abstract}

The current interest and focus on STEM education is largely a response to affective issues related to participation and engagement in mathematics and science. Concerns about low levels of interest and engagement are key factors in students opting out of these subjects, attaining low levels of achievement leading to declining enrolments and concerns about shortages in people taking up STEM focused careers. This has created a sense of urgency and stakeholders have seen STEM education as a way to ameliorate these issues and concerns. However, the issues are, at least partially, fundamentally affective in nature, and so the response of educators to the current crisis must also be 'affective'. In this chapter we examine the philosophical and theoretical foundations of current STEM education approaches, and then interrogate current research relating to STEM education, with a particular focus on Australia, to examine whether affective issues are central in current STEM initiatives.

\section{Introduction}

STEM education has been identified as a path to address a global need for contemporary societies to transform, innovate, adjust and adapt (Lowrie, Downes, \& Leonard, 2017). In education, STEM has also been viewed as a response to affective issues relating to participation, interest and engagement in the individual disciplines of mathematics and science (Becker \& Park, 2011; National Research Council, 2014). In 2005 a recommendation was handed down by the OECD that governments take action to address the decline in students studying science, technology, engineering and mathematics (STEM) due to declining participation rates (OECD, 2006). Well over a decade later the global STEM agenda continues to build momentum yet there is evidence that during the past ten years the proportion of upper secondary and tertiary level students studying in STEM fields has continued to decline (Hughes, Luo, Kwok, \& Loyd, 2008; Roberts, 2013; Wang \& Degol, 2014). Over the past two decades participation rates in senior secondary science and mathematics in particular have declined in Australian schools and internationally (Kennedy, Lyons, \& Quinn, 2014), having a direct impact on students entering STEM related fields. In the Australian context, Kennedy et al. claim that although the scale of declining enrolments is unclear, government and industry bodies are concerned and feel these declines must be addressed. These continuing declines in enrolments and participation imply that current policy and programs relating to STEM in schools are not delivering the desired outcomes and affective issues appear to continue to remain a significant influence. 
In this chapter we explore the current STEM context, focusing on affect in STEM. We interrogate policy and existing programs to determine whether student affect is considered and addressed within STEM programs and we propose that one of the underlying factors contributing to the challenges of STEM programs is the lack of attention given to improving affect and consequently achievement in the individual disciplines of mathematics and science. First, we briefly draw on literature to establish a definition of STEM for this chapter. We then provide clarification of 'affect' in relation to STEM and our discussions. This is followed by a discussion of student engagement and the challenges experienced in promoting positive engagement with mathematics and science. Finally, we explore STEM policies and programs to examine whether affective issues are central in current STEM education initiatives.

\section{Defining STEM Education}

It is challenging to find a common definition of STEM as it pertains to education. English (2017) refers to the myriad of viewpoints and the contentious nature of STEM with regard to the often unequal attention given to the four disciplines (Lowrie, Downes, et al., 2017; National Research Council, 2014). A definition from Shaughnessy (2013) highlights the mathematics and science embedded within STEM: "STEM education refers to solving problems that draw on concepts and procedures from mathematics and science while incorporating the team work and design methodology of engineering and using appropriate technology" (p.324). Although there are debates regarding the inclusion of other disciplines such as the arts, for the purpose of this chapter we draw on Shaughnessy's definition.

Just as it is difficult to find a common definition of STEM, it is similarly challenging to find a consistency amongst exemplars of STEM practice in schools. This is perhaps due to the fact that STEM research is an emerging field and there is no specific STEM curriculum in Australia nor a specific engineering curriculum. According to Siekmann (2016), STEM education and training seeks to establish relationships between the four disciplines for the purpose of improving scientific and technical skills via an emphasis on critical and creative thinking. Lowrie et al. (2017) provide a synopsis of the current approaches to STEM practices ranging from a treatment as individual discipline areas to a more common integration or fusion of all or some of the four disciplines with a focus on contextualised real-world experiences (Siekmann, 2016).

The integrated approach to STEM is noted to have several advantages, including the potential to improve affective elements such as interest and motivation. However, a metaanalysis of STEM related research by Becker and Park (2011) failed to reveal studies that measured the influence of integrated STEM education on affect. A more recent analysis of research into the integrated STEM approach (National Research Council, 2014) revealed some evidence of improved academic achievement and indicated that integrated STEM programs or interventions such as school-based projects and curriculum units can support the development and maintenance of interest and identity in STEM, yet more research is required. It is believed that a disadvantage of the integrated STEM approach is that the individual disciplines of mathematics and engineering are often neglected due to an increased focus on technology (Lowrie et al., 2017; National Research Council, 2014). 
Lowrie et al. (2017) cite further disadvantages to the integrated STEM approach including time limitations for teachers to master a different pedagogical approach, challenges in separating content knowledge and assessment, and issues in addressing learning outcomes. Lowrie et al. propose a shift away from focusing on content knowledge to a focus on STEM practices that encompass ideas, methods and values (Lowrie, Logan, \& Larkin, 2017). This shift away from a focus on content knowledge may be one way of addressing affective issues in STEM:

It is concerned with how forms of understanding are connected to individual and collective self-expression, how modes of action are connected to individual and collective self-development, and how ways of relating to one another are connected to individual and collective empowerment and self-determination. (p.26)

While there may be an alternative approach to STEM education as proposed by Lowrie et al. (2017) we cannot address affective issues without a clear understanding of what they entail. The following is a brief outline of the affective domain and its relation to STEM education.

\section{Affect and STEM}

The affective domain has been a long-standing educational concern, particularly in subjects like mathematics and science that have historically been seen as emotionally difficult for some. Although there have been studies looking at affective aspects of education for over 70 years, it perhaps became more prominent in the 1980s with particular concerns about the participation of girls in STEM subjects (e.g., Vale \& Leder 2004). At this time it became important to consider not only the cognitive and psychomotor learning of students, but also the affective dimension of their learning.

However, over the years what constitutes the affective domain has been unclear and variously defined (Grootenboer \& Marshman, 2017), and this has led to a lack of clarity about some of the related research and educational development. A seminal understanding of the affective domain was outlined by Krathwohl, Bloom, and Masia (1964), alongside the widely known Bloom's taxonomy (Bloom, \& Krathwohl, 1956). The affective domain of Krathwohl, Bloom and Masia included aspects that focused on attitudes, awareness, attention, concern, interest, and responsibility. Later, a range of other models and conceptualisations were developed that tried to delineate what was 'affective', and how the various affective aspects related to one another. One was developed by Grootenboer (2003) who included beliefs, values, attitudes and emotions (see Figure 1) 


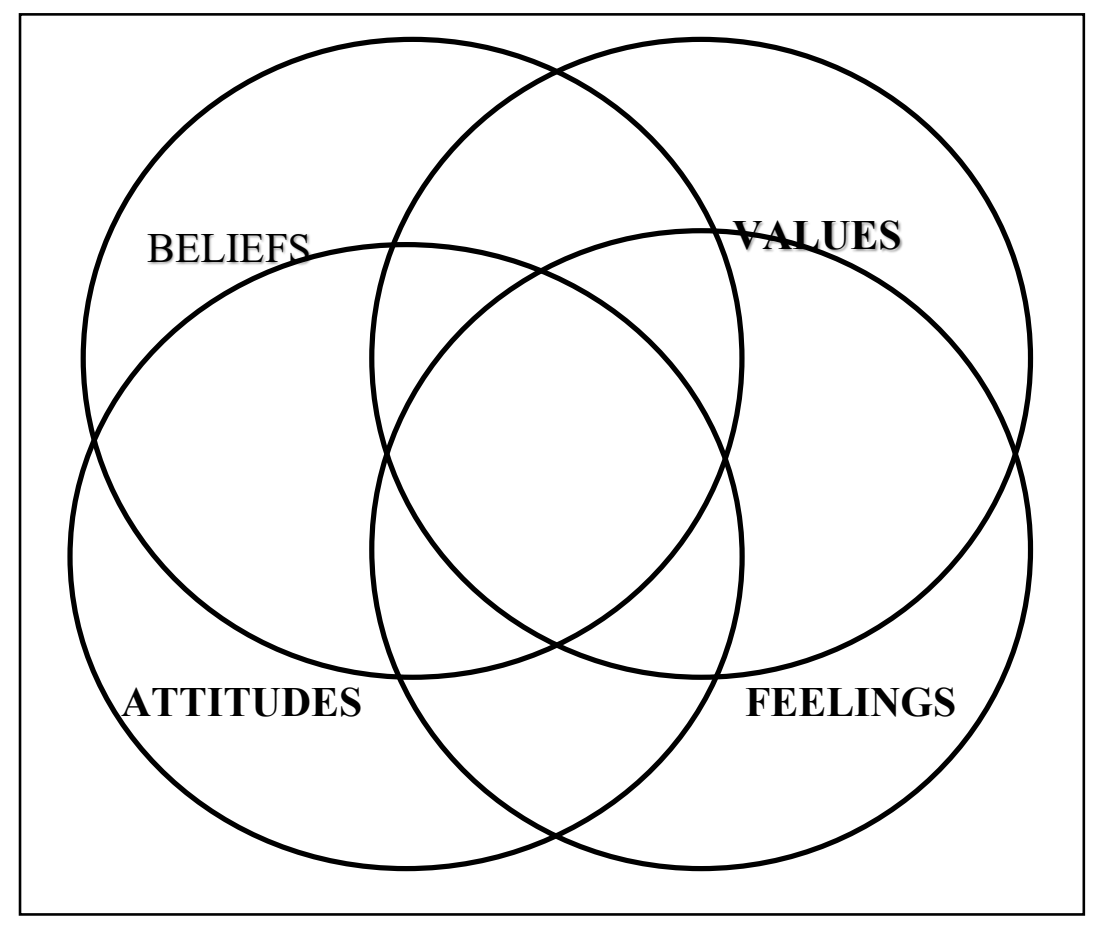

Figure 1: The Affective Domain (Grootenboer, 2003)

In this understanding of the affective domain, beliefs are seen as more cognitive, and less temporal than emotions. Of course, there are others who have defined the affective domain differently, with for example, some including beliefs and/or values (e.g., McLeod, 1992) and others not, while others have included aspects like identity (e.g., Lerman, 2009).

Furthermore, while the initial work in this area was primarily undertaken within a psychological tradition, affect has now been considered in a broad range of academic traditions including sociology (e.g., Lerman, 2009) and psychotherapy (e.g., Brown, Brown, \& Biddy, 2008). Thus, the affective domain, and how it relates to education, is a murky topic, particularly due to the lack of clarity about what affect is, and both how it is learned and how it impacts learning, in STEM.

There is not scope here to provide a deep and robust outline of the affective domain, but we will now briefly outline how it will be defined and what will be included, as we consider affect in relation to STEM education. In the end, we are not so much concerned about providing a definitive conceptualisation of affect, but rather how the various aspects work holistically to impact learning in STEM, and how these can lead to greater student engagement.

Beliefs, as defined by Philipp (2007) are "psychologically held understandings, premises, or propositions about the world that are thought to be true" (p. 259), and as such beliefs impact how an individual sees the world and responds to it. In terms of STEM education, beliefs therefore filter new experiences and information, and in this way they can moderate the content and the processes of student learning. Historically, some of the individual STEM disciplines have been hampered by beliefs that are not necessarily representative of the 
world (i.e., accurate) and/or helpful for students learning in that discipline, and perhaps the newness and novelty of STEM can ameliorate some of these tradition belief-based barriers.

Attitudes are less 'cognitive' than beliefs, and more 'emotive', and are seen to develop as either positive or negative response to repeated experiences. Thus, attitudes are relatively stable, and they act as "predispositions to action which invoke preferential responses to the event or object concerned" (Grootenboer \& Marshman, 2017, p. 19). As with beliefs, attitudes - both positive and negative, are seen to both influence learning and engagement, and to be the outcome of school experiences.

Emotions and Feelings are temporal unstable affective responses to a particular situation, event or experience, and can include a wide range including excitement, fear, joy, panic, boredom and frustration. Again, students will experience emotions as an integral part of learning, and these can impact students' engagement in their learning, and their developing beliefs and attitudes towards STEM and learning in STEM.

Interest is also a common affective quality that is focused upon in the science and STEM literature, and includes to a greater or lesser degree the aspects noted above. Interest is multi-faceted, and is seen as a forerunner to engagement and participation (Christidou, 2011) There are other components of the affective domain including confidence, selfesteem, self- efficacy, dispositions and fun, and some even include notions of identity in discussions of affect in education. These are all inter-related, and together all these affective qualities/responses are the outcome of STEM learning and engagement, but also impact STEM learning and engagement.

\section{Student Engagement}

The construct of engagement is one that is often misunderstood and underestimated in education, yet is one of the driving forces behind the current STEM agenda in schools. Although the term is used frequently by researchers and teachers alike, it is often simply perceived as students who being compliant, on task, and well behaved. However, the construct is more complex and represents a much deeper relationship with work and learning, with serious implications for what we teach and how we teach it. For the purpose of this chapter, we present a definition of engagement and some clarification of the reciprocal relationship between engagement and motivation. Although there are a variety of definitions for engagement, it is typically defined as a combination of behaviour, affect and cognition (Fredricks, Blumenfeld, \& Paris, 2004). Behavioural engagement (sometimes referred to as operative engagement) encompasses the idea of active participation and involvement. Cognitive engagement relates to the idea of investment and recognition of the value of learning, and affective engagement encompasses students' reactions to school, including teachers and peers. Viewed in this multi-dimensional way, engagement can be defined as the coming together of the three facets: behavioural, affective and cognitive (Fair Go Team NSW Department of Education and Training, 2006), leading to students enjoying, valuing, and making connections with STEM concepts both within and beyond the classroom. Arguably, if students are more deeply engaged in STEM during the school years, academic achievement should improve, leading to more students taking up further study in 
STEM related fields and addressing the national agenda of improving Australia's capacity to be competitive in the global market (ref? perhaps link to chief scientist).

The terms engagement and motivation are often closely associated, yet although both are driven by cognition, the constructs are very different (Fredricks et al., 2004; Ryan, 2000). Engagement signifies the actions and behaviours that are a result of motivation: that is, the individual's relationship with school, curriculum and pedagogy (Attard, 2013). When a student is engaged with learning, he or she has been influenced by motivation, yet on its own motivation is driven by one's beliefs and one's drive to engage and work effectively (Martin, 2008; Wang \& Degol, 2014). The cognitions underpinning motivation can be encapsulated by two questions: 'Can I do my schoolwork?' and "Do I want to do my schoolwork and why?' (Ryan, 2000), where the cognitions relating to engagement are projected outwards towards schoolwork, involving a student's investment and effort towards learning and the utilisation of specific learning strategies in order to achieve learning goals. Knowledge of student motivation can influence teachers and their expectations of students, the way their classes are structured and the way curriculum is delivered. When teachers adapt their practices to improve or maintain motivation this in turn influences student engagement and achievement levels (Martin, 2005). STEM education potentially provides important opportunities for improving student motivation and engagement due to the hands-on and operative nature of the individual discipline areas. However, we are concerned existing school disengagement within the disciplines of mathematics and science may hinder the intent of STEM initiatives if they are not addressed.

\section{Engagement with Mathematics, Science and STEM}

Arguably the foundations of STEM are formed within the disciplines of mathematics and science, yet these are two key school subjects that continue to be a challenge in relation to developing and maintaining high levels of student engagement that result in students continuing their study beyond the compulsory years. Student engagement is considered a key contributing factor to academic success and continued study in mathematics and science is (Barker, Dowson, \& Mclnerney, 2005; Hughes et al., 2008; Maltese \& Tai, 2010; Wang \& Degol, 2014). If educators expect students to develop substantive engagement and achieve academic success in STEM, we argue that issues of engagement in mathematics and science must first be identified and addressed to ensure the implementation of STEM initiatives delivers the intended results. Improved academic success in the disciplines of mathematics and science are critical if students are to successfully apply the knowledge and skills from the individual disciplines to STEM related learning.

Issues in engagement with mathematics and science during the school years have long been of international concern (Attard, 2014; Everingham, Gyuris, \& Connolly, 2017; Maltese \& Tai, 2010). The middle years of schooling are specifically well documented in literature for being a critical time in the formulation of positive attitudes towards mathematics. It is a widely held belief that it is during this time that adolescents make the decision to withdraw from or continue the study of science or mathematics due to experiences that occur within the classroom (Australian Curriculum Board, 2009; Maltese \& Tai, 2010). Of further concern is emerging evidence that disengagement and negative attitudes may form even earlier in 
students' lives (Commonwealth of Australia, 2008; Larkin \& Jorgensen, 2015). This has created a sense of urgency in terms of addressing the causes of disengagement and perhaps provides sound justification for the implementation of STEM programs from the early years of schooling.

There are similarities amongst the issues and influences on student engagement in mathematics and science as documented by Kennedy et al. (2014) who claim there are 'blockers' in both disciplines when it comes to students enrolling in senior secondary mathematics and sciences courses: "self-perception of ability, perceptions of difficulty and usefulness, previous achievement, and interest and liking of mathematics" (p.44). Arguably these 'blockers' may be linked to student affect and engagement in the early and middle years of schooling. Further extending this sentiment, Ainley and Ainley claim: "students bring to their learning a legacy of thoughts and feelings associated with earlier learning experiences and this history colours engagement" (2011, p. 4). Declines in engagement with mathematics and science are often attributed to similar factors. A lack of curriculum relevance, pedagogical practices that focus on content consumption, a lack of connection within and amongst mathematics topics or scientific disciplines and perceptions that mathematics and science are difficult and inaccessible are commonly listed as influences on student engagement (Boaler, 2009; Christidou, 2011; Maltese \& Tai, 2010; Patrick, Ryan, \& Kaplan, 2007; Simon \& Osborne, 2010). However, research by Attard (2013) revealed the teacher as the core influence on engagement. This influence was articulated through the Framework for Engagement with Mathematics (FEM) (Attard, 2014) (Figure 2) which details two separate yet inter-related elements of teacher practice that influence engagement: pedagogical relationships and pedagogical repertoires. Pedagogical relationships refer to the interpersonal teaching and learning relationships between teachers and students that optimize the learning of and engagement with mathematics. Pedagogical repertoires refer to the teaching practices that are employed by the teacher in day-to-day teaching. Although the FEM is specific to mathematics, it is reasonable to conclude that these elements would also influence engagement with science. Similarities between the ideas, methods and values that comprise Lowrie et al.'s (2017) STEM Practices model and the FEM, along with the hands-on and contextualised nature of integrated STEM tasks suggest that the development of pedagogical relationships along with appropriate STEM related pedagogical repertoires could reasonably eventuate in cognitive, operative and affective engagement. However, such development would require significant teacher professional learning opportunities. Such opportunities are often reliant on policy to which we now turn, to explore how and if the affective domain is acknowledged and addressed. 


\begin{tabular}{|c|c|c|}
\hline Aspect & Code & Element \\
\hline \multirow[t]{6}{*}{$\begin{array}{l}\text { Pedagogical } \\
\text { Relationships }\end{array}$} & \multicolumn{2}{|r|}{$\begin{array}{l}\text { In an engaging mathematics classroom, positive pedagogical relationships exist where these elements } \\
\text { occur: }\end{array}$} \\
\hline & PK & $\begin{array}{l}\text { Pre-existing Knowledge: students' backgrounds and pre-existing knowledge are acknowledged } \\
\text { and contribute to the learning of others }\end{array}$ \\
\hline & $\mathrm{Cl}$ & $\begin{array}{l}\text { Continuous Interaction: interaction amongst students and between teacher and students is } \\
\text { continuous }\end{array}$ \\
\hline & PCK & $\begin{array}{l}\text { Pedagogical Content Knowledge: the teacher models enthusiasm and an enjoyment of } \\
\text { mathematics and has a strong Pedagogical Content Knowledge }\end{array}$ \\
\hline & TA & $\begin{array}{l}\text { Teacher Awareness: the teacher is aware of each student's mathematical abilities and learning } \\
\text { needs }\end{array}$ \\
\hline & $\mathrm{CF}$ & Constructive Feedback: feedback to students is constructive, purposeful and timely \\
\hline \multirow{7}{*}{$\begin{array}{l}\text { Pedagogical } \\
\text { Repertoires }\end{array}$} & \multicolumn{2}{|c|}{ Pedagogical repertoires include the following aspects: } \\
\hline & SC & $\begin{array}{l}\text { Substantive Conversation: there is substantive conversation about mathematical concepts and } \\
\text { their applications to life }\end{array}$ \\
\hline & $\mathrm{CT}$ & $\begin{array}{l}\text { Challenging Tasks: tasks are positive, provide opportunity for all students to achieve a level of } \\
\text { success and are challenging for all }\end{array}$ \\
\hline & PC & Provision of Choice: students are provided an element of choice \\
\hline & ST & $\begin{array}{l}\text { Student-centred Technology: Technology is embedded and used to enhance mathematical } \\
\text { understanding through a student-centred approach to learning }\end{array}$ \\
\hline & RT & $\begin{array}{l}\text { Relevant Tasks: the relevance of the mathematics curriculum is explicitly linked to students' lives } \\
\text { outside the classroom and empowers students with the capacity to transform and reform their } \\
\text { lives }\end{array}$ \\
\hline & VT & $\begin{array}{l}\text { Variety of Tasks: mathematics lessons regularly include a variety of tasks that cater to the diverse } \\
\text { needs of learners }\end{array}$ \\
\hline \multicolumn{3}{|c|}{$\begin{array}{l}\text { Students are engaged with mathematics when: } \\
\text { - Mathematics is a subject they enjoy learning (affective) } \\
\text { - They value mathematics learning and see its relevance in their current and future lives, and } \\
\text { - They see connections between the mathematics learned at school and the mathematics used beyond the } \\
\text { classroom }\end{array}$} \\
\hline
\end{tabular}

Figure 2: The Framework for Engagement with Mathematics (FEM) (Attard, 2014).

\section{STEM Policy: Addressing Affective Issues?}

In describing STEM policy, we are referring to frameworks for STEM-specific objectives as reflected in legislation, policy or strategy statements (Marginson, Tytler, Freeman, \& Roberts, 2013). The motivation around the need for STEM policy and the generation of a 'pipeline' of STEM education at both school and tertiary level concern the strengthening of the STEM labour force. An educational pathway for students in STEM fields is considered instrumental in promoting economic growth and wellbeing and responds to the major skill shortages in STEM-based industries (Marginson et al., 2013; Watters \& Diezmann, 2013). 
Globally there appears to be a range of objectives and approaches regarding STEM legislation and policy. These generally concern supporting increased achievement in STEM by promoting engagement and through content revision and pedagogy reform (Marginson et al., 2013). This is particularly emphasised at the primary and lower secondary level through intervention programs that claim to focus on engaging all students in mathematics and science in order to increase the intake of students into STEM related subjects in higher education. This agenda is particularly targeted towards under-represented groups.

In generating curriculum reform, whether it be general or specifically related to science and mathematics, there are many competing choices to be considered (Marginson et al., 2013). In Asian countries, who are already demonstrating greater success in STEM programs, as illustrated in PISA results, there is a shift of focus from disciplinary knowledge to nurturing creativity, problem solving, collaboration and higher order thinking. Australia's policy discourse is largely borrowed from Europe, the United States and other nations (Lowrie, Leonard \& Fitzgerald, 2018). Many western countries choose a focus on inquiry in science and problem solving in mathematics, when choosing a STEM curriculum focus (Marginson et al., 2013). There appears to be a common theme globally on the purpose of STEM to promote student engagement, academic success, and preparedness for the workforce through inquiry and problem solving, Asian countries consistently outperform the rest of the world, and the gap continues to grow. This is usually credited to a culture that has maintained a high value for education, greater quality of teachers, employment of evidence based practice, and a collective 'push' at a national level, and Asia's success is likely one of the motives for Australia's desire to improve international rankings and increase its global competitiveness.

Despite Australia's shift to the promotion of engagement in STEM subjects through real world settings, legislation is still yet to translate to practice. 'Translation and impact', as described by Lowrie et al., (2018) remain a challenge. That is, current research has largely failed to create knowledge that is usable, scalable and sustainable. This usable knowledge is widely recognised as a result of successful school-community partnerships whereby students gain industry knowledge and engage in educational experiences that value innovation and creativity (Office of the Queensland Chief Scientist, 2013; Watters \& Diezmann, 2013). This is referred to as a process of 'curriculum setting' when referring to higher university programs being responsive to the occupations that STEM graduates are preparing to enter (Office of the Chief Scientist, 2013).

Further, the Australian Government has signified that within their vision of a successful STEM education system there must be a rise of the prestige and preparedness of teachers, both by upskilling pre-service and practicing teachers and attracting high achievers in STEM to the profession. It is in the government's third suggestion that the clarity fades, suggesting we "think bold, collaborate and lead change" (Prinsley \& Johnston, 2015, p. 1). Thus, a national approach to STEM education is discussed but not specified in the detail required for implementation. Many Australian Government documents released over the last decade support these suggestions documents (for example, Department of Education and Training, 2018; Office of the Chief of Science, 2013; Prinsley \& Johnston, 2015), however there is little mandating or provision of specific guides regarding the implementation of these ideas in actual school settings outside of the specific mandatory Science and Mathematics State 
Syllabus documents. Although there is a National Curriculum for Technologies (Australian Curriculum and Reporting Authority, 2018), at a state level this content does not appear in its own document but is rather found in the state science syllabi. By teaching content and skills from each discipline separately, their real life application is not demonstrated, instead hoping that students will see the connections (Timms, Moyle, Weldon, \& Mitchell, 2018).

Given the emphasis placed on pedagogical reform in Australia, it is surprising that there has been no mandating of STEM specific professional development for teachers. For instance, a National STEM School Education Strategy, 2016-2026 was introduced in 2015 by the Australian Education ministers (Education Council, 2015). The two main goals of this policy are to ensure students finish school with strong foundation STEM skills and to inspire students to take on more challenging STEM subjects. One of the five strategies suggested to achieve these goals is to increase student STEM ability, engagement participation and aspiration. The policy describes this action as follows:

\begin{abstract}
Students' early interest in STEM is not translating to ongoing engagement and participation in STEM education. While evidence shows students have a natural interest in science, they don't necessarily understand the relevance of STEM education, particularly maths. Research shows that there is an interrelationship between student aspirations towards STEM careers and engagement in STEM subjects. Mathematical thinking is a fundamental skill that underpins all STEM learning. The sequential nature of mathematical learning means that students who fall off the 'maths pathway' early can struggle to achieve sufficient levels of mathematical literacy. $(2015$, p. 8)
\end{abstract}

This quote strengthens the argument we present in this chapter that affective issues in both mathematics and science need to be addressed in order for STEM initiatives to have lasting and sustainable impacts. As mentioned above, the suggested strategies from the Education Council are relevant and reflective of evidence based practice, however there are no practical suggestions or mandated changes within the classroom setting. The 'action' suggested in the report rather is to make subjects mandatory in secondary education and acknowledge the greater load of advanced STEM subjects through initiatives such as a university entrance bonus point scheme.

On a smaller scale, each Australian state and territory government have released policies that reference STEM in education. The commonalities of these policies include three priorities; student outcomes, teacher workforce and curriculum (Timms et al., 2018). In their Challenges in STEM Learning in Australian Schools Literature and Policy Review, Timms et al. highlight the alarming reality of the effect of STEM National strategy in Australia, despite these state and national efforts for reform. In addressing a 2003 report, Australia's Teachers, Australia's Future, which explores the advancement of innovation, science, technology and mathematics, a very grim reality is highlighted: "A great deal has been written on the importance of STEM to Australia's future. It is therefore concerning that a report written this long ago still accurately portrays the present state of affairs." (Timms et al., 2018, p. 9). Significantly here, these issues can be seen to be, at least partially, affective in nature.

\title{
STEM Programs in Australian Schools: Addressing Affect?
}


There are a multitude of significant STEM initiatives being implemented in Australian schools, school systems, universities, within communities and the business domain to encourage STEM education. The Department of Education and Training document, Support for Science, Technology, Engineering and Mathematics (STEM), (2018) lists a few of these government funded programmes that have been implemented to improve STEM education in Australian. Under the 'Inspiring STEM Literacy' measure of the 'National Innovation and Science Agenda', the government funds school-based programs such as 'Early Learning STEM initiatives', 'Let's Count', 'Little Scientists', and 'Early Learning STEM Research'. Similarly, the government funds programs to support teachers in implementing quality STEM education in schools. 'Science by Doing', 'Primary Connections: Linking Science with Literacy', 'ReSolve: Maths by Inquiry', 'Digital Technologies Hub' and 'Coding Across the Curriculum' are websites that provide comprehensive online resources and activities that are freely available to teachers that also aim to enhance their confidence and competence in STEM education (Sharma \& Yarlagadda, 2018). The government furthermore funds a number of STEM education programs that take place outside of the school environment. 'Diglt', which targets groups under-represented in STEM, and 'Curious Minds', which targets high-achieving female students, are ICT Summer Schools for students from Years 9 and 10. They involve a series of summer schools that gives these targeted students a chance to participate in digital technologies and explore related careers.

The descriptions and proposed aims of several of these school-based programs appear to have some affective objectives. The Department of Education and Training (2018) document conveys that the aim of the 'Early Learning Stem Initiatives' program is to "promote positive learning experiences for children". Similarly, the same document suggests that is provides the opportunity for "families and children to take part in fun and exciting STEM activities" and that it will "inspire curiosity and interest in STEM among preschool-aged children". The program, 'Little Scientists', was designed to help educators "lead fun inquiry-based learning activities" while the 'Little Scientists' website voices that "children need to be given the opportunity to explore the world in a nurturing and playful setting that boosts their natural eagerness to learning" (Little Scientists, 2019). The residential camp, 'Curious Minds' is described as a "mentoring program with the aim of igniting girls' passion and participation in STEM" (Department of Education, and Training, 2018) while the 'Curious Minds' creators express their vision to "contribute to building Australian's scientific community through inspiring and developing our best science students" (Australian science innovations, c2019). The 'reSolve: Maths by Inquiry' program was designed to "help students learn mathematics in fun and innovative ways" (Department of Education and Training, 2018) while the 'Science by Doing' similarly is an "inquiry-based approach to lift student interest and understanding" (Science by Doing, 2019). As observed, these government-funded program express having affective intentions to engage students in STEM. However, there seems to be no evidence of how these intentions flow through to the classroom or even a successful connection being made to the affective domain of engagement or the robust literature behind it.

\section{Affect and STEM}


Although not explicitly related to 'affect' or 'affective engagement', Martin-Hansen (2018) explores how a positive or negative science, technology, engineering and mathematics experiences affect the formation of an individual's STEM identity. She clarifies how presenting STEM concepts and ideas is not merely enough to guarantee student interest, enjoyment or that they are deeply internalizing the knowledge. Martin-Hansen explains that STEM concepts are not universal ideas, but rather they are human endeavours that are inevitably sifted through an individual's lenses of personal experience when one is attempting to make meaning of them. Therefore, when learning and teaching STEM related subjects, it should be acknowledged that an individual's culture and belief system are relevant at all periods of inquiry and problem solving. If students are to be recruited and retained in STEM fields, they need to have a positive STEM social identity (Martin-Hansen, 2018).

Although there are a considerable number of government funded STEM education programs being implemented throughout Australia, it cannot be ignored that current literature frequently suggests a continuous decline in STEM enrolment as there is a declining interest in STEM related subjects in western countries (Sharma \& Yarlagadda, 2018; Watters \& Diezmann, 2013). Additionally, although the importance of STEM to today's society is acknowledged, there still remains considerable skills shortages in STEM-based industries (Watters \& Diezmann, 2013). The literature frequently suggests the common goal of 'engaging', 'inspiring', 'motivating' and increasing the 'aspirations' and 'interests' of Australian students to participate in STEM related subjects. Signified in a STEM article which outlined perspectives of STEM education policies, it was stated that, "a policy centre piece of the Turnbull Government announced in December 2015, to 'inspire' all Australians - from pre-schoolers to the broader community - to engage with STEM" (Sharma \& Yarlagadda, 2018). Similarly, these authors specified that, "governments are committed to train and inspire the youth of their nations and produce skilled workforce that would make invaluable contributions to their STEM industries" and also that "declining enrolment trends in STEM education have forced policy makers to take serious steps in creating an interest and motivating children towards the undertaking of STEM education" (Sharma \& Yarlagadda, 2018). In the 2017 STEM Partnerships Forum chaired by Australia's Chief Scientist Dr Alan Finkel, it states that "the challenge for increasing participation in STEM disciplines is building aspiration" (Education Council, 2018, p.46). Although these keys words all insinuate the collective objective of endorsing a positive emotional/affective disposition to STEM participation, it is seldom seen that an authentic investigation into the affective domain of students' engagement in STEM education is thoroughly or deeply explored. Alternatively, what has been observed in the literature, is an almost cryptic application of these emotionally/affectively-inclined words without any distinctive definition. These words are all widely used in the STEM literature without any successful connection being made to their uniting and highly theoretical concept 'affective engagement'.

\section{Conclusions and Implications}

In this chapter we have demonstrated the inherently affective nature of STEM education, and indeed, how many policy-makers and educators have seem STEM as a panacea for the affective ills facing the disciplines of mathematics and science. Unfortunately, it is clear that while there has been widespread hope for these STEM initiatives to promote participation, 
interest, and engagement in its constituent disciplines, and in turn higher learning outcomes, there appears to have been little detail about how this might be achieved, clarity about why it might work, and research to measure its success. Indeed, there is some evidence that participation in science, mathematics and engineering has not improved. Simply repackaging what have historically been unpopular, but important, disciplines (i.e., mathematics and science) in a new "STEM" wrapper will not automatically improve student engagement and therefore, participation and achievement. Perhaps this is because currently, the complex issues related to engagement, participation and achievement in STEM, and its disciplines, have been dealt with in an overly simplistic manner, and inadequate attention have been afforded to the affective dimension of learning. We think that the emerging work of Lowrie, Logan and Larkin (2017) on "STEM practices" is a useful way to consider STEM education in a more sophisticated manner.

This is not to say that a STEM approach may not improve student engagement and participation, but there is a need for more complex research and theorising, particularly now the initial basic work has been undertaken as the euphoria and promise of STEM initiatives were rolled out. Below we suggest some implications for research and practice

\section{Implications for Research}

First, in general there would seem to be a pressing need for research that pays particular and focused attention to the affective dimension of learning STEM. This would mean moving beyond the assumption that STEM is inherently interesting, motivating and engaging. Importantly, it needs to examine the way affect influences and impacts learning in STEM, but also what and how affective qualities are developed through STEM pedagogies. This would require conceptualising STEM and affect in holistic and complex ways, and not overly simplifying them in the research process and subsequent theorising.

Second, it would seem timely to consider how affective qualities in STEM education are 'learned', and importantly how this relates to the foundation school disciplines of mathematics and science. For example, it is well known that many people dislike mathematics and subsequently disengage from mathematics education, but is this ameliorated by STEM education initiatives? More specifically, is STEM in schools addressing all three dimensions of engagement, or is it just affective and operative (hands-on) and not cognitive because the science and mathematics content knowledge is not being accessed or is not strong enough?

Third, it appears that enrolments in STEM related fields are still dropping, so there is a need to understand if the supposed engagement and interest engendered by 'STEM' at school actually connects to STEM disciplines in tertiary education. And if this disengagement is due to affective factors (amongst others), how could this be addressed? Perhaps there is a need for longitudinal research on affect and STEM between school and tertiary to further examine this disconnect, especially given the aspirations and hopes for school STEM education to ameliorate this worrying concern. 
Of course, there are many more worthwhile avenues for research into the affective domain and STEM education, but it will be important that alongside this research there is careful analysis and theorising. As noted above, the idea of "STEM practices" is one example of how this might be done, and this would appear to be worthwhile as it attends to the actual 'doing' of science, technology, engineering and mathematics, and has relevance for classroom practice in STEM.

\section{Implications for Classrooms}

While we do not want to create an artificial divide between research and practice, alongside, and related to, the implications for research, there are some implications for classrooms. Here we list three.

First, if there is a disconnect between the STEM experienced by students at school, and the STEM of the world outside of classrooms, there is a need to reconsider the curriculum. Specifically, how can this be addressed in the classroom through initiatives such as stronger links to industry, and how does the 'realness' of school STEM activities impact interest and engagement, and beliefs about mathematics and science.

Second, for a range of reasons it would seem important to prioritise mathematics and science within school STEM learning. Shaughnessy's (2013) definition of STEM highlighted the foundational nature of mathematics and science, and this has been reiterated by the Chief Scientist in Australia. Furthermore, across the world these two disciplines are fundamental parts of the curriculum, and as such provide the substantive 'prior learning' when it comes to studying in STEM. This is not to assume that the nature and quality of pedagogy and learning in mathematics and science does not require attention, but here we are suggesting that improving engagement and interest in STEM will be built on an emphasis on these subjects, including and especially the affective dimension of learning in them. To this end, there is scope with current curricula to do this through syllabus features like 'mathematical proficiencies' and 'scientific processes'.

Finally, the promises of STEM-based reforms will not be realised without specific attention to staff development. Specifically, teachers need time, support and education so they can develop their own STEM practices, and importantly their attitudes, confidence and knowledge. This is not to eschew the need for teachers to develop relevant pedagogical knowledge and skills, but if they are to foster student interest and engagement in STEM, then they need to be interested and engaged in STEM themselves.

\section{Final Comment}

Affect is an integral part of learning in any area of the curriculum, and STEM is no different. It is not an appendage that needs to be considered as separate and disconnected for developing knowledge and skills, but rather it is a part of learning that both is shaped, and shapes, what is learned and how it is learned. Furthermore, affective qualities and responses are learned through classroom experiences. It seems to us that in general an 
agenda for STEM education has largely arisen to try and address diminishing interest and participation in mathematics and science, and at this point it is unclear as to whether this has been effective, apart from largely anecdotal and hearsay accounts from STEM disciples. For this reason we have suggested that it is time for a more theoretically robust and sophisticated understanding of STEM education, that includes, in an integrated manner, the affective domain and Attard's FEM.

\section{References:}

Ainley, M., \& Ainley, J. (2011). Student engagement with science in early adolescence: The contribution of enjoyment to students' continuing interest in learning about science. Contemporary Educational Psychology, 36(1), 4-12. https://doi.org/10.1016/j.cedpsych.2010.08.001

Attard, C. (2013). "If I had to pick any subject, it wouldn't be maths": foundations for engagement with mathematics during the middle years. Mathematics Education Research Journal, 25(4), 569-587. https://doi.org/10.1007/s13394-013-0081-8

Attard, C. (2014). "I don't like it, I don't love it, but I do it and I don't mind": Introducing a framework for engagement with mathematics. Curriculum Perspectives, 34, 1-14.

Australian Curriculum and Reporting Authority (2018) Digital Technologies. Retrieved from https://www.australiancurriculum.edu.au/f-10-curriculum/technologies/digitaltechnologies/

Australian Curriculum Board. (2009). Shape of the Australian Curriculum: Mathematics. Commonwealth of Australia.

Australian science innovations. (2019). Australian Science Innovations. Retrieved 6 February, 2019, from https://www.asi.edu.au/about/australian-science-innovations/

Barker, K., Dowson, M., \& Mclnerney, D. M. (2005, December). Effects between motivational goals, academic self-concept and academic achievement: What is the causal ordering? Presented at the Australian Association of Educational Research (AARE), Sydney.

Becker, K., \& Park, K. (2011). Effects of integrative approaches among science, technology, engineering, and mathematics (STEM) subjects on students' learning: A preliminary meta-analysis. Journal of STEM Education : Innovations and Research; Auburn, 12(5/6), 23-37.

Bloom, B. S. \& D. R. Krathwohl. (1956). Taxonomy of educational objectives: The classification of educational goals, by a committee of college and university examiners. Handbook 1: Cognitive domain. New York, Longmans.

Boaler, J. (2009). The elephant in the classroom: Helping children learn and love maths. London: Souvenir Press Ltd.

Brown, M., Brown, P., \& Biddy, T. (2008). I would rather die: Reasons given by 16-year-olds for not continuing their study of mathematics. Research in Mathematics Education, 10(1), 3-18.

Christidou, V. (2011). Interest, Attitudes and Images Related to Science: Combining Students' Voices with the Voices of School Science, Teachers, and Popular Science. International Journal of Environmental and Science Education, 6(2), 141-159.

Commonwealth of Australia. (2008). National numeracy review report. Canberra, ACT: Human Capital Working Group, Council of Australian Governments. 
Department of Education and Training. (2018). Support for Science, Technology, Engineering and Mathematics (STEM) Retrieved February 5, 2019, from https://www.education.gov.au/support-science-technology-engineering-andmathematics

Education Council. (2015). National STEM School Eduation Strategy, 2016-2026. Retrieved from

http://www.educationcouncil.edu.au/site/DefaultSite/filesystem/documents/Nation al\%20STEM\%20School\%20Education\%20Strategy.pdf

Education Council. (2018). Optimising STEM industry-school partnerships: Inspiring Australia's next generation final report. Carlton South, Vic.: Education Council.

English, L. D. (2017). Advancing Elementary and Middle School STEM Education. International Journal of Science and Mathematics Education, 15(1), 5-24. https://doi.org/10.1007/s10763-017-9802-x

Everingham, Y. L., Gyuris, E., \& Connolly, S. R. (2017). Enhancing student engagement to positively impact mathematics anxiety, confidence and achievement for interdisciplinary science subjects. International Journal of Mathematical Education in Science and Technology, 48, 1153-1165.

Fair Go Team NSW Department of Education and Training. (2006). School is for me: pathways to student engagement. Sydney: NSW Department of Education and Training, Sydney, Australia.

Fredricks, J. A., Blumenfeld, P. C., \& Paris, A. H. (2004). School engagement: Potential of the concept, state of the evidence. Review of Educational Research, 74(1), 59 -110.

Grootenboer, P. (2003). Preservice primary teachers' affective development in mathematics. Unpublished doctoral dissertation, University of Waikato, NZ.

Grootenboer, P., \& Marshman, M. (2017). Mathematics, affect and learning: Middle school students' beliefs and attitudes about mathematics education. Singapore: Springer

Hughes, J. N., Luo, W., Kwok, O.-M., \& Loyd, L. K. (2008). Teacher-student support, effortful engagement, and achievement: A 3-year longitudinal study. Journal of Educational Psychology, 100(1), 1-14. https://doi.org/10.1037/0022-0663.100.1.1

Kennedy, J., Lyons, T., \& Quinn, F. (2014). The continuing decline of science and mathematics enrolments in Australian high schools. Teaching Science, 60(2), 34-46.

Krathwohl, D. R., Bloom, B. S., \& Masia, B. B. (1964). Taxonomy of educational objectives, Book 2: Affective domain. Upper Saddle River, NJ: Pearson Education

Larkin, K., \& Jorgensen, R. (2015). 'I Hate Maths: Why Do We Need to Do Maths?' Using iPad Video Diaries to Investigate Attitudes and emotions towards mathematics in Year 3 and Year 6 students. International Journal of Science and Mathematics Education, 14, 925-944.

Lerman, S. (2009). Pedagogy, discourse, and identity. In L. Black, H. Mendick, \& Y. Solomon (Eds.), Mathematical relationships in education: Identities and participation (pp. 147-155). New York, NY: Routledge.

Little scientists. (2019). Little Scientists. Retrieved 6 February, 2019, from https://littlescientists.org.au/about/

Lowrie, T., Downes, T., \& Leonard, S. (2017). STEM Education for all young Australians. A Bright Spots STEM Learning Hub Foundation Paper for SVA, in partnership with Samsung. University of Canberra STEM Education Research Centre. 
Lowrie, T., Leonard, S., \& Fitzgerald, R. (2018). STEM Practices: A translational framework for large-scale STEM education design. EDeR. Educational Design Research, 2(1). https://doi.org/10.15460/eder.2.1.1243

Lowrie, T., Logan, T., \& Larkin, K. (2017). The "math" in STEM practices: The role of spatial reasoning in the early years. Symposium - STEM practices: A reconceptualization of STEM in the early years. In S. L. A. Downton (Ed.). Presented at the 40 Years on: We are still learning. Proceedings of the 40th Annual Conference of the Mathematics Education Research Group of Australasia., MERGA.

Maltese, A., \& Tai, R. (2010). Eyeballs in the Fridge: Sources of early interest in science: International Journal of Science Education: Vol 32, No 5. International Journal of Science Education, 32(5), 669-685.

Marginson, S., Tytler, R., Freeman, R., \& Roberts, K. (2013). STEM: Country comparisons. Melbourne, Vic.: Australian Council of Learned Academies.

Martin, A. J. (2008). Enhancing student motivation and engagement: The effects of a multidimensional intervention. Contemporary Educational Psychology, 33, 239-269.

Martin, A. J. (2005). Can students' motivation and engagement change? Findings from two intervention studies. Paper presented at the Association for Research in Education Focus Conference, Cairns, Qld. http://www.aare.edu.au/05pap/mar05425.pdf

Martin-Hansen, L. (2018). Examining ways to meaningfully support students in STEM. International Journal of STEM Education, 5(1), 53. https://doi.org/10.1186/s40594$\underline{018-0150-3}$

McLeod, D. B. (1992). Research on affect in mathematics education: A reconceptualization. In D. Grouws (Ed.), Handbook of research on mathematics teaching and learning (pp. 575-596). New York: Macmillan.

National Research Council. (2014). STEM Integration in K-12 Education: Status, Prospects, and an Agenda for Research. Washington, D.C.: The National Academies Press.

OECD. (2006). Evolution of student interest in science and technology studies: Policy report (p. 18). Paris: OECD.

Office of the Queensland Chief Scientist. (2013). Roadmap to STEM education in Queensland. Retrieved from

https://www.chiefscientist.qld.gov.au/documents/pubs/stem/roadmap-stem-eduin-qld.pdf

Patrick, H., Ryan, A. M., \& Kaplan, A. (2007). Early adolescents' perceptions of the classroom social environment, motivational beliefs, and engagement. Journal of Educational Psychology, 99, 83-98.

Philipp, R. A. (2007). Mathematics teachers' beliefs and affect. In F. K. Lester, Jr. (Ed.) Second handbook of research on mathematics teaching and learning (pp. 257-315). Charlotte, NC: Information Age.

Prinsley, R., \& Johnston, E. (2018). Transforming STEM teaching in Australian primary schools: Everybody's business. Canberra: Office of the Chief Scientist.

Roberts, A. (2013). Stem Is Here. Now What? Technology and Engineering Teacher; Reston, 73(1), 22-27.

Ryan, A. M. (2000). Peer groups as a context for the socialisation of adolescents' motivation, engagement and achievement in school. Educational Psychologist, 25(2), 101-111.

Science by doing. (c2019). Science by Doing. Retrieved 6 February, 2019, from https://www.sciencebydoing.edu.au/about-the-program 
Sharma, J., \& Yarlagadda, P. (2018). Perspectives of 'STEM education and policies' for the development of skilled workforce in Australia and India. International Journal of Science Education, 40(16), 1999-2022.

Shaughnessy, J. M. (2013). Mathematics in a STEM Context. Mathematics Teaching in the Middle School, 18(6), 324-324. https://doi.org/10.5951/mathteacmiddscho.18.6.0324

Siekmann, G. (2016). What is STEM? The need for unpacking its definitions and applications. National Centre for Vocational Education Research. Retrieved from https://www.ncver.edu.au/_data/assets/pdf_file/0023/61349/What-is-STEM.pdf

Simon, S., \& Osborne, J. (2010). Students' attitudes to science. In Good practice in science teaching: What research has to say (2nd ed., pp. 211-237). Berkshire, UK: Open University Press.

Timms, M., Moyle, K., Weldon, P., \& Mitchell, P. (2018). Challenges in STEM learning in Australian schools (Policy Insights Issue 7). Camberwell, Victoria: ACER.

Vale, C., \& Leder, G. C. (2004). Student views of computer-based mathematics in the middle years: Does gender make a difference? Educational Studies in Mathematics, 56, 287312.

Wang, M.-T., \& Degol, J. (2014). Staying Engaged: Knowledge and Research Needs in Student Engagement. Child Development Perspectives, 8(3), 137-143. https://doi.org/10.1111/cdep.12073

Watters, J. J., \& Diezmann, C. M. (2013). Models of Community Partnerships for Fostering Student Interest and Engagement in STEM. Journal of STEM Education: Innovations and Research, 14(2). Retrieved from http://www.jstem.org/index.php/JSTEM/article/view/1681

Author Bios:

Catherine Attard is an Associate Professor in Primary Mathematics Education and Deputy Director of the Centre for Educational Research at Western Sydney University. Catherine's research is focused on student engagement with mathematics and issues surrounding the pedagogical practices that influence students' engagement. Catherine is also actively researching contemporary teaching practices through the use of digital technologies. Catherine has won several teaching awards, including a 2016 Australian Awards for University Teaching (AAUT) Teaching Excellence Award and an Office of Learning and Teaching citation for Outstanding Contributions to Student Learning.

Peter Grootenboer was a school teacher and leader for 12 years before moving into the tertiary sector. He received the national Jim Campbell Award for teaching excellence. He is now a Professor of Education at Griffith University and the Deputy Director of the Griffith Institute for Educational Research. His research interests include mathematics education, educational leadership, practice/praxis theory, and action research. 
Elise Attard is a primary school teacher in Sydney, New South Wales. She is currently undertaking a Master of Research degree at Western Sydney University. Her research involves mathematics education in Australian primary schools and the influence that classroom teachers have on students' attitudes towards, and achievement in mathematics.

Alexandra Laird is a primary school teacher and higher degree research student. Since graduating with a BEd (Primary), she has worked in a number of schools and taught classes at a range of levels. She has completed a Masters of Education via research and worked on a number of research projects. Alexandra's main area of focus is student engagement in mathematics education. 